\title{
Predictive Factors to Distinguish Between Patients With Noncomplicated Appendicitis and Those With Complicated Appendicitis
}

\author{
Tae Hyung Kim, Byung Sun Cho, Jae Hag Jung, Moon Soo Lee, Je Ho Jang, Chang Nam Kim \\ Department of Surgery, Eulji University Hospital, Eulji University School of Medicine, Daejeon, Korea
}

Purpose: Recently, randomized controlled trials have reported that conservative therapy can be a treatment option in patients with noncomplicated appendicitis. However, preoperative diagnosis of noncomplicated appendicitis is difficult. In this study, we determined predictive factors to distinguish patients with noncomplicated appendicitis from those with complicated appendicitis.

Methods: A total of 351 patients who underwent surgical treatment for acute appendicitis from January 2011 to December 2012 were included in this study. We classified patients into noncomplicated or complicated appendicitis groups based on the findings of abdominal computed tomography and pathology. We performed a retrospective analysis to find factors that could be used to discriminate between noncomplicated and complicated appendicitis.

Results: The mean age of the patients in the complicated appendicitis group (54.5 years) was higher than that of the patients in the noncomplicated appendicitis group $(40.2$ years $)(\mathrm{P}<0.001)$, but the male-to-female ratios were similar. In the univariate analysis, the appendicocecal junction's diameter, appendiceal maximal diameter, appendiceal wall enhancement, periappendiceal fat infiltration, ascites, abscesses, neutrophil proportion, C-reactive protein (CRP), aspartate aminotransferase, and total bilirubin were statistically significant factors. However, in the multivariate analysis, the appendiceal maximal diameter $(\mathrm{P}=0.018$; odds ratio $[\mathrm{OR}], 1.129)$, periappendiceal fat infiltration $(\mathrm{P}=0.025 ; \mathrm{OR}, 5.778)$, ascites $(\mathrm{P}=0.038 ; \mathrm{OR}, 2.902)$, and $\mathrm{CRP}(\mathrm{P}<0.001 ; \mathrm{OR}, 1.368)$ were statistically significant.

Conclusion: Several factors can be used to distinguish between noncomplicated and complicated appendicitis. Using these factors, we could more accurately distinguish patients with noncomplicated appendicitis from those with complicated appendicitis.

Keywords: Appendicitis; Appendectomy

\section{INTRODUCTION}

Acute appendicitis is a common disease with a lifetime risk of $7 \%$ to $8 \%$ in the United States [1]. Since Fitz [2]'s study published in

Received: September 25, 2015 - Accepted: October 13, 2015

Correspondence to: Byung Sun Cho, M.D.

Department of Surgery, Eulji University Hospital, Eulji University School of

Medicine, 95 Dunsanseo-ro, Seo-gu, Daejeon 35233, Korea

Tel: +82-42-611-3064, Fax: +82-42-259-3858

E-mail: sunjoe@eulji.ac.kr

(c) 2015 The Korean Society of Coloproctology

This is an open-access article distributed under the terms of the Creative Commons Attribution NonCommercial License (http://creativecommons.org/licenses/by-nc/3.0) which permits unrestricted non-

commercial use, distribution, and reproduction in any medium, provided the original work is properly cited.
1886, an early appendectomy has been accepted as the best treatment for acute appendicitis. Although surgical treatment is well tolerated by most patients, it is associated with a risk of postoperative complications occurring in about $2 \%$ to $23 \%$ of the patients $[3,4]$. Additionally, several studies have reported that $3 \%$ of the patients who underwent an appendectomy with or without laparoscopy were readmitted for mechanical obstruction related to a postoperative complication $[5,6]$.

Three previous randomized controlled trials reported that the one-year cure rate for patients with noncomplicated appendicitis who were treated with antibiotics was $74 \%-87 \%$ and that conservative therapy could be a treatment option for patients with acute appendicitis [7-9]. Recently, a randomized controlled trial by Salminen et al. [10] reported that antibiotic treatment for noncom- 
plicated appendicitis was inferior to surgical treatment. These studies tried to use conservative therapy to treat patients with noncomplicated appendicitis, but not patients with complicated appendicitis. However, the preoperative diagnosis of patients with noncomplicated appendicitis was challenging. In this study, we attempted to determine the factors that could be used to distinguish patients with complicated appendicitis using preoperative laboratory data, computed tomography (CT) findings, and postoperative pathology findings.

\section{METHODS}

The study subjects were 351 patients who had undergone surgical treatment for acute appendicitis between January 2011 and December 2012 at Eulji University Hospital. Inclusion criteria were age older than 18 years and diagnosis based on a CT scan. We excluded patients who were age younger than 18 years old because three previous randomized controlled trials had used adult patients (age $>18$ years) [7-9]. Other exclusion criteria were pregnancy and inflammatory bowel disease combined with an appendiceal neoplasm. A retrospective analysis was done by reviewing the medical records of the included patients. Patient gender, age, preoperative laboratory markers (white blood cell [WBC], neutrophil proportion, C-reactive protein [CRP], total bilirubin, aspartate aminotransferase [AST], and alanine aminotransferase [ALT]), and abdominal CT findings (appendiceal maximal diameter, appendicocecal junction's diameter, appendiceal wall enhancement, periappendiceal fat infiltration, appendicolith, abscesses, and ascites) were recorded. All patients were classified into two groups (noncomplicated appendicitis vs. complicated appendicitis). Patients with appendicitis with perforation or gangrenous changes on pathology or periappendiceal abscess on operative findings were classified as having complicated appendicitis. If the postoperative pathologic finding was a normal appendix or simple appendicitis without complication, the patients were classified as having noncomplicated appendicitis.

We performed statistical analysis using PASW Statistics ver. 18.0 (SPSS Inc., Chicago, IL, USA). The chi-square test was used to check for differences between proportions. The Student t-test was used for comparisons of continuous variables between groups. The sensitivities, the specificities, and the odds ratios (ORs) were calculated for the factors that discriminated between the noncomplicated and the complicated appendicitis groups. A P-value of $\leq 0.05$ was used to indicate statistical significance.

\section{RESULTS}

\section{Patient characteristics}

Of the 351 patients, 240 (69\%) were diagnosed with simple appendicitis, 85 patients (24\%) were diagnosed with complicated appendicitis, and 26 patients (7\%) were diagnosed with a normal appendix. The negative appendectomy rate was $7 \%$. The mean
Table 1. Patient characteristics

\begin{tabular}{lccr}
\hline Characteristic & $\begin{array}{c}\text { Noncomplicated } \\
\text { appendicitis }\end{array}$ & $\begin{array}{c}\text { Complicated } \\
\text { appendicitis }\end{array}$ & P-value \\
\hline No. of patients (\%) & $266(77)$ & $85(23)$ & $<0.001$ \\
Age (yr), mean (range) & $40.2(18-87)$ & $54.48(23-91)$ & $<0.001$ \\
Sex & $128: 138$ & $41: 44$ & 0.684 \\
$\quad$ Male:female & $4.25 \pm 1.5$ & $7.52 \pm 3.9$ & $<0.001$ \\
\hline Hospital stay (day), mean \pm SD & & & \\
\hline
\end{tabular}

The number of patients with noncomplicated appendicitis was the sum of those with a normal appendix and those with acute appendicitis without perforation or gangrenous changes on the pathology findings. The number of patients with complicated appendicitis was the sum of those with acute appendicitis with perforation or gangrenous changes on the pathology findings and those with a periappendiceal abscess on the operative findings.

$\mathrm{SD}$, standard deviation.

age was 40.2 years (18 to 87 years) for the patients with noncomplicated appendicitis and 54.5 years ( 23 to 91 years) for those with complicated appendicitis. The mean age of the patients in the complicated appendicitis group was significantly higher than that of those in the noncomplicated appendicitis group $(\mathrm{P}<0.001)$. Of the patients, 169 were male and 182 were female. The male-to-female ratios were similar in the two groups. However, the number of females with a negative appendectomy was double that of males with a negative appendectomy group. The mean hospital stay was 4.25 days (standard deviation $[\mathrm{SD}], \pm 1.5$ ) and 7.52 days $(\mathrm{SD}, \pm 3.9)$ for the noncomplicated and the complicated appendicitis groups, respectively (Table 1).

\section{CT findings}

The mean appendicocecal junction's diameters $(\mathrm{P}<0.001)$ and the appendiceal maximal diameters $(\mathrm{P}<0.001)$ were significantly higher in the complicated appendicitis group compared with the noncomplicated appendicitis group. Appendiceal wall enhancement $(P=0.01)$, periappendiceal fat infiltration $(P<0.001)$, ascites $(\mathrm{P}<0.001)$ and abscesses $(\mathrm{P}<0.001)$ were detected with a significantly higher frequency in the complicated appendicitis group (Table 2).

\section{Laboratory findings}

The neutrophil proportion $(\mathrm{P}=0.004)$ and the $\mathrm{CRP}(\mathrm{P}<0.001)$, total bilirubin $(\mathrm{P}<0.001)$, and AST levels $(\mathrm{P}=0.049)$ were significantly higher in the complicated appendicitis group compared with the noncomplicated appendicitis group. No significant differences in ALT levels $(\mathrm{P}=0.308)$ and mean WBCs $(\mathrm{P}=0.014)$ were seen between the two groups $(\mathrm{P}=0.308)$ (Table 3$)$.

\section{Factors that discriminate between the noncomplicated and the complicated groups}

In the univariate analysis, the appendicocecal junction's diameter, appendiceal maximal diameter, appendiceal wall enhancement, 
Table 2. Univariate analysis of computed tomography findings (noncomplicated appendicitis vs. complicated appendicitis)

\begin{tabular}{lccc}
\hline Variable & $\begin{array}{c}\text { Noncomplicated } \\
\text { appendicitis }\end{array}$ & $\begin{array}{c}\text { Complicated } \\
\text { appendicitis }\end{array}$ & P-value \\
\hline $\begin{array}{l}\text { Appendicocecal junction's } \\
\quad \text { diameter (mm) }\end{array}$ & $7.48 \pm 2.2$ & $8.85 \pm 3.1$ & $<0.001$ \\
$\begin{array}{l}\text { Appendiceal maximal } \\
\quad \text { diameter (mm) }\end{array}$ & $9.82 \pm 3.1$ & $11.87 \pm 3.4$ & $<0.001$ \\
$\begin{array}{l}\text { Appendiceal wall enhancement } \\
\text { Periappendiceal fat infiltration }\end{array}$ & $187 / 266(70)$ & $83 / 85(98)$ & $<0.001$ \\
Appendicolith & $70 / 266(26)$ & $27 / 85(32)$ & $<0.001$ \\
Ascites & $13 / 266(5)$ & $23 / 85(27)$ & $<0.001$ \\
Abscess & $0 / 266(0)$ & $28 / 85(33)$ & $<0.001$ \\
\hline
\end{tabular}

Values are presented as mean \pm standard deviation or number (\%). The number of patients with noncomplicated appendicitis was the sum of those with a normal appendix and those with acute appendicitis without perforation or gangrenous changes on the pathologic findings. The number of patients with complicated appendicitis was the sum of those with acute appendicitis with perforation or gangrenous changes on the pathology findings and those with a periappendiceal abscess on the operative findings.

Table 3. Univariate analysis of the laboratory findings (noncomplicated appendicitis vs. complicated appendicitis)

\begin{tabular}{lccr}
\hline Laboratory finding & $\begin{array}{c}\text { Noncomplicated } \\
\text { appendicitis }\end{array}$ & $\begin{array}{c}\text { Complicated } \\
\text { appendicitis }\end{array}$ & P-value \\
\hline WBC $(1,000 / \mu \mathrm{L})$ & $12.57 \pm 4.1$ & $13.38 \pm 4.4$ & 0.124 \\
Neutrophil proportion $(\%)$ & $76.33 \pm 12.4$ & $80.55 \pm 8.9$ & 0.004 \\
CRP $(\mathrm{mg} / \mathrm{dL})$ & $2.05 \pm 2.8$ & $11.47 \pm 8.4$ & $<0.001$ \\
AST $(\mathrm{IU} / \mathrm{L})$ & $24.74 \pm 16.5$ & $29.06 \pm 20.2$ & 0.049 \\
ALT $(\mathrm{IU} / \mathrm{L})$ & $21.27 \pm 18.7$ & $23.68 \pm 19.4$ & 0.308 \\
Total bilirubin $(\mathrm{mg} / \mathrm{dL})$ & $0.95 \pm 0.4$ & $1.24 \pm 0.7$ & $<0.001$ \\
\hline
\end{tabular}

Values are presented as mean \pm standard deviation. The number of patients with noncomplicated appendicitis was the sum of those with a normal appendix and those with acute appendicitis without perforation or gangrenous changes on the pathology findings. The number of patients with complicated appendicitis was the sum of those with acute appendicitis with perforation or gangrenous changes on the pathology findings and those with a periappendiceal abscess on the operative findings.

WBC, white blood cell; CRP, C-reactive protein; AST, aspartate aminotransferase; ALT, alanine aminotransferase.

periappendiceal fat infiltration, ascites, abscesses, neutrophil proportion, and CRP, AST, and total bilirubin levels were significantly different between the noncomplicated and the complicated groups. However, in the multivariate analysis, a reverse stepwise logistic regression analysis of the data comparing the noncomplicated and the complicated appendicitis groups demonstrated that the appendiceal maximal diameter $(\mathrm{P}=0.018$; $\mathrm{OR}, 1.129)$, periappendiceal fat infiltration $(\mathrm{P}=0.025$; $\mathrm{OR}, 5.778)$, ascites $(\mathrm{P}=0.038$; $\mathrm{OR}$, $2.902)$, and $\mathrm{CRP}$ level $(\mathrm{P}<0.001$; OR, 1.368) were statistically significant factors. The sensitivities of periappendiceal fat infiltration,
Table 4. Multivariate analysis of complicated appendicitis vs. noncomplicated appendicitis

\begin{tabular}{lcccc}
\hline Variable & P-value & Odds ratio & Sensitivity & Specificity \\
\hline $\begin{array}{l}\text { Appendiceal maximal } \\
\quad \text { diameter }>10 \mathrm{~mm}\end{array}$ & 0.018 & 1.129 & 0.73 & 0.53 \\
$\begin{array}{l}\text { Periappendiceal fat infiltration } \\
\text { Ascites }\end{array}$ & 0.025 & 5.778 & 0.94 & 0.30 \\
$\mathrm{CRP}>5 \mathrm{mg} / \mathrm{dL}$ & 0.038 & 2.902 & 0.27 & 0.95 \\
\hline
\end{tabular}

CRP, C-reactive protein.

Table 5. Scoring system based on the laboratory data and the computed tomography scans

\begin{tabular}{lc}
\hline Variable & Score \\
\hline Appendiceal maximal diameter $>10 \mathrm{~mm}$ & 1 \\
Ascites & 1 \\
Periappendiceal fat infiltration & 1 \\
$\mathrm{CRP}>5 \mathrm{mg} / \mathrm{dL}$ & 1 \\
\hline
\end{tabular}

Score $>2$ : sensitivity, 0.89 ; specificity, 0.94 .

CRP, C-reactive protein.

appendiceal maximal diameter, ascites, and CRP level were 0.94, $0.73,0.27$, and 0.78 , respectively. The specificities of ascites, appendiceal maximal diameter, periappendiceal fat infiltration, and CRP level were $0.95,0.53,0.30$, and 0.90 , respectively (Table 4 ).

\section{Scoring system}

In this study, through analysis of preoperative lab data, abdominal CT scans, and postoperative pathology findings, we attempted to provide a diagnostic criterion that could distinguish patients with noncomplicated appendicitis from those with complicated appendicitis. The adopted variables were the appendiceal maximal diameter $(>10 \mathrm{~mm})$, periappendiceal fat infiltration, and ascites on CT findings and CRP $(>5 \mathrm{mg} / \mathrm{dL})$ (Table 5$)$. One point was assigned to each variable, adding up to a total of four points. The mean score for the complicated appendicitis group $(2.63 \pm 0.87$ points) was significantly higher than that for the noncomplicated appendicitis group $(1.17 \pm 0.85$ points $)(\mathrm{P}=0.459)$. The area under the curve of the receiver operating characteristics curve was shown to be 0.870 (Fig. 1). If we adopted a score of two to diagnose complicated appendicitis, that score had a sensitivity of 0.89 and a specificity of 0.68 .

\section{DISCUSSION}

Conservative therapy as a treatment for patients with acute appendicitis started after Coldrey [11]'s study in 1959 on 471 patients with acute appendicitis who had received antibiotics as a single treatment. Since then, three different randomized controlled trials, which were performed by Hasson et al. [7], Styrud et 


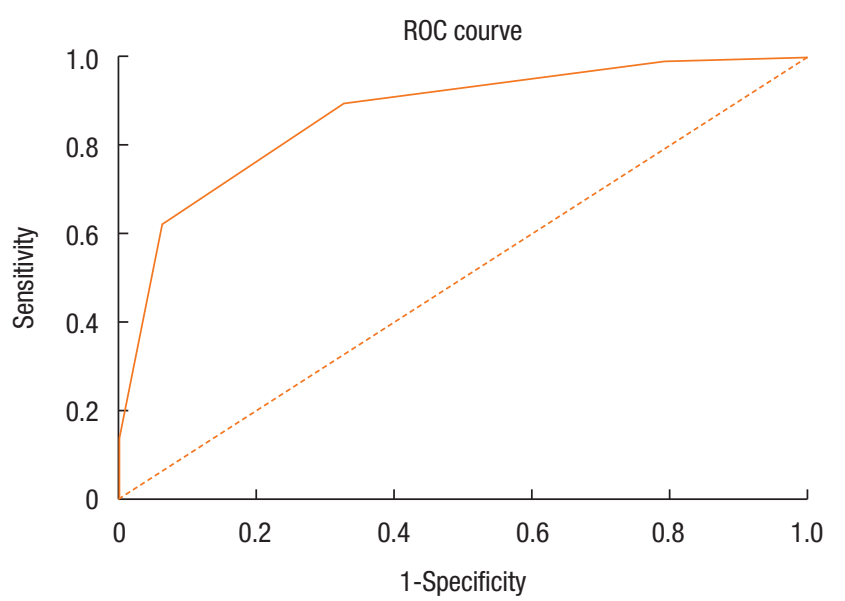

Fig. 1. Receiver operating characteristics (ROC) curve for the scoring system based on the laboratory data and the computed tomography scans. The area under the ROC curve is 0.870 ( $95 \%$ confidence interval, 0.825-0.915).

al. [8], and Vonns et al. [9], respectively, demonstrated that treatment with antibiotics could be as safe and effective as an appendectomy for patients with noncomplicated appendicitis. However, the recent randomized controlled trial of Salminen et al. [10] reported that the 1-year cure rates for an appendectomy and antibiotic treatment were $99.6 \%$ and $72.3 \%$, respectively, but they failed to prove that surgical treatment was superior to conservative therapy for patients with noncomplicated appendicitis. Antibiotic treatment for patients with noncomplicated appendicitis was still a subject prolific of controversy, but the effort to distinguish noncomplicated appendicitis from complicated appendicitis was meaningful [12]. Two studies, which were performed by Vonns et al. [9] and Saminen et al. [10], respectively, gave CT-based criteria to diagnose complicated appendicitis. Styrud et al. [8] used laboratory criteria to distinguish noncomplicated appendicitis from complicated appendicitis.

In this study, we analyzed both the preoperative laboratory data and CT scans and found factors that could be used to distinguish between patients with noncomplicated and those with complicated appendicitis. In the multivariate analysis, appendiceal maximal diameter $(>10 \mathrm{~mm})$, periappendiceal fat infiltration, ascites, and CRP level $(>5 \mathrm{mg} / \mathrm{dL})$ were significantly different between the noncomplicated appendicitis and the complicated appendicitis groups. Eleven patients who were diagnosed with complicated appendicitis had four predictive factors. However, no patient in the noncomplicated appendicitis group had four predictive factors (Table 6).

Before CT was invented, the diagnosis of acute appendicitis was based on symptoms, signs, and laboratory data. The utility of a CT scan in cases of acute appendicitis enabled high accuracy in early diagnosis and reduced morbidity attributed to perforation. It had a high sensitivity (0.99) and specificity (0.95) [13]. The ap-
Table 6. Predictive factor scores (noncomplicated appendicitis vs. complicated appendicitis)

\begin{tabular}{lccc}
\hline Predictive factor score & $\begin{array}{c}\text { Noncomplicated } \\
\text { appendicitis }\end{array}$ & $\begin{array}{c}\text { Complicated } \\
\text { appendicitis }\end{array}$ & P-value \\
\hline 0 & 54 & 1 & $<0.001^{\text {a }}$ \\
1 & 126 & 8 & \\
2 & 72 & 22 & \\
3 & 20 & 38 & \\
4 & 0 & 11 & \\
\hline
\end{tabular}

Predictive factors were appendiceal maximal diameter $>10 \mathrm{~mm}$, periappendiceal fat infiltration, ascites, and C-reactive protein $>5 \mathrm{mg} / \mathrm{dL}$. Predictive factor score was the sum of the predictive factors that patients had.

aPearson chi-square test.

pendiceal maximal diameter $(>7 \mathrm{~mm})$ and periappendiceal fat infiltration were important diagnostic findings of acute appendicitis $[14,15]$. However, the distinction between non-complicated and complicated appendicitis remained difficult, even with CT scans $[16,17]$. Vonns et al. [9] used CT-based criteria to diagnose complicated appendicitis (extra luminal gas, periappendiceal fluid, disseminated intraperitoneal fluid, and appendix diameter $>15$ $\mathrm{mm})$. A total of 119 patients underwent surgical treatment for suspected noncomplicated appendicitis. However, 21 patients (18\%) were diagnosed with complicated appendicitis after surgery. CT alone was not enough to distinguish between noncomplicated and complicated appendicitis [9]. In our study, we found that appendiceal maximal diameter $(>10 \mathrm{~mm})$, periappendiceal fat infiltration, and ascites on CT scans were highly associated with complicated appendicitis. The presence of periappendiceal fat infiltration had a high sensitivity (0.94), and ascites had a high specificity (0.95).

Recently, one meta-analysis reported that procalcitonin and CRP levels and WBC could be predictive factors that distinguish between noncomplicated and complicated appendicitis [18]. Also, in a study by Noh et al. [19], WBC and CRP and bilirubin levels were useful clinical markers in the diagnosis of complicated appendicitis. A study by Zhao et al. [20] reported that hyperfibrinogenemia might be useful as a predictive factor for appendiceal perforation. Several studies reported that hyperbilirubinemia $(>1.0 \mathrm{mg} / \mathrm{dL})$ and CRP level $(>5 \mathrm{mg} / \mathrm{dL})$ were statistically significant markers of perforation in patients with acute appendicitis $[21,22]$. Furthermore, one study reported that WBC and CRP level were associated with postoperative complications. When $\mathrm{WBC}>16,500 / \mu \mathrm{L}$ and CRP level $>3.1 \mathrm{mg} / \mathrm{dL}$, complications increased six times [23]. In our study, leukocytosis, hyperbilirubinemia, and CRP elevation were significantly different between the noncomplicated and the complicated appendicitis groups in the univariate analysis. However, in the multivariate analysis, CRP level $(>5 \mathrm{mg} / \mathrm{mL})$ was the only significant factor.

Recently, Atema et al. [12] made a scoring system based on clinical and imaging features to distinguish noncomplicated from 
complicated appendicitis. The age, body temperature, duration of symptoms, WBC, CRP level, extraluminal free air on imaging, periappendiceal fluid on imaging, and appendicolith on imaging were included. The sensitivity and the specificity were 0.96 and 0.45 , respectively [12]. In our scoring system, the appendiceal maximal diameter $(>10 \mathrm{~mm})$, periappendiceal fat infiltration and ascites on CT findings and CRP level $(>5 \mathrm{mg} / \mathrm{dL})$ were included. The sensitivity and the specificity were 0.89 and 0.68 , respectively (Table 5). Furthermore, this score had a high sensitivity and specificity compared with the score based on only the appendiceal maximal diameter (sensitivity, 0.73 ; specificity, 0.53 ), only periappendiceal fat infiltration (sensitivity, 0.94 ; specificity, 0.30 ), only ascites (sensitivity, 0.27; specificity, 0.95), and only the CRP level (sensitivity, 0.78 ; specificity, 0.90 ) as predictive factors of complicated appendicitis.

An appendectomy is well tolerated by most patients. However, it is associated with a risk of a negative appendectomy and surgical wound infection. In this study, we performed an abdominal CT on all patients to diagnose acute appendicitis. However, the negative appendectomy rate was 7\%. In a recent study, the negative appendectomy rate was $15 \%$ to $25 \%$. This rate could be as high as $40 \%$ in female patients [24-26]. In our hospital, the negative appendectomy rate in females has been twice that in males. Several studies have reported the rate of surgical wound infection to be $5 \%-30 \%[27,28]$. In this study, we had 42 complications. Surgical site infection and ileus were found in $33(9 \%)$ and 7 of the cases (2\%); intra-abdominal abscesses were observed in two patients.

This study had several limitations. Firstly, this was a retrospective study. In our hospital, patients with acute appendicitis undergo emergency surgery. Hence, an operation delay may lead to a mismatch between the preoperative state and the postoperative diagnosis. Therefore, a follow-up randomized controlled study is necessary.

In conclusion, in this study, the appendiceal maximal diameter, periappendiceal fat infiltration, ascites, and CRP level were factors that were statistically different between the noncomplicated and the complicated appendicitis groups. Using these factors, we could more accurately distinguish patients with noncomplicated appendicitis from those with complicated appendicitis patients.

\section{CONFLICT OF INTEREST}

No potential conflict of interest relevant to this article was reported.

\section{REFERENCES}

1. Addiss DG, Shaffer N, Fowler BS, Tauxe RV. The epidemiology of appendicitis and appendectomy in the United States. Am J Epidemiol 1990;132:910-25.

2. Fitz RH. Perforating inflammation of the vermiform appendix. Am J Med Sci 1886;92:321-46.
3. Konstantinidis KM, Anastasakou KA, Vorias MN, Sambalis GH, Georgiou MK, Xiarchos AG. A decade of laparoscopic appendectomy: presentation of 1,026 patients with suspected appendicitis treated in a single surgical department. J Laparoendosc Adv Surg Tech A 2008;18:248-58.

4. Ming PC, Yan TY, Tat LH. Risk factors of postoperative infections in adults with complicated appendicitis. Surg Laparosc Endosc Percutan Tech 2009;19:244-8.

5. Parker MC, Ellis H, Moran BJ, Thompson JN, Wilson MS, Menzies D, et al. Postoperative adhesions: ten-year follow-up of 12,584 patients undergoing lower abdominal surgery. Dis Colon Rectum 2001;44:822-9.

6. Leung TT, Dixon E, Gill M, Mador BD, Moulton KM, Kaplan $\mathrm{GG}$, et al. Bowel obstruction following appendectomy: what is the true incidence? Ann Surg 2009;250:51-3.

7. Hansson J, Korner U, Khorram-Manesh A, Solberg A, Lundholm K. Randomized clinical trial of antibiotic therapy versus appendicectomy as primary treatment of acute appendicitis in unselected patients. Br J Surg 2009;96:473-81.

8. Styrud J, Eriksson S, Nilsson I, Ahlberg G, Haapaniemi S, Neovius $\mathrm{G}$, et al. Appendectomy versus antibiotic treatment in acute appendicitis. a prospective multicenter randomized controlled trial. World J Surg 2006;30:1033-7.

9. Vonns C, Barry C, Maitre S, Pautrat K, Leconte M, Costaglioli B, et al. Amoxicillin plus clavulanic acid versus appendicectomy for treatment of acute uncomplicated appendicitis: an open-label, non-inferiority, randomised controlled trial. Lancet 2011;377: 1573-9.

10. Salminen P, Paajanen H, Rautio T, Nordstrom P, Aarnio M, Rantanen T, et al. Antibiotic therapy vs appendectomy for treatment of uncomplicated acute appendicitis: the APPAC Randomized Clinical Trial. JAMA 2015;313:2340-8.

11. Coldrey E. Five years of conservative treatment of acute appendicitis. J Int Coll Surg 1959;32:255-61.

12. Atema JJ, van Rossem CC, Leeuwenburgh MM, Stoker J, Boermeester MA. Scoring system to distinguish uncomplicated from complicated acute appendicitis. Br J Surg 2015;102:979-90.

13. Apisarnthanarak P, Suvannarerg V, Pattaranutaporn P, Charoensak A, Raman SS, Apisarnthanarak A. Alvarado score: can it reduce unnecessary CT scans for evaluation of acute appendicitis? Am J Emerg Med 2015;33:266-70.

14. Nelson DW, Causey MW, Porta CR, McVay DP, Carnes AM, Johnson EK, et al. Examining the relevance of the physician's clinical assessment and the reliance on computed tomography in diagnosing acute appendicitis. Am J Surg 2013;205:452-6.

15. Duda JB, Lynch ML, Bhatt S, Dogra VS. Computed tomography mimics of acute appendicitis: predictors of appendiceal disease confirmed at pathology. J Clin Imaging Sci 2012;2:73.

16. Horton MD, Counter SF, Florence MG, Hart MJ. A prospective trial of computed tomography and ultrasonography for diagnosing appendicitis in the atypical patient. Am J Surg 2000;179:379-81.

17. Pinto Leite N, Pereira JM, Cunha R, Pinto P, Sirlin C. CT evalua- 
tion of appendicitis and its complications: imaging techniques and key diagnostic findings. AJR Am J Roentgenol 2005;185:406-17.

18. Yu CW, Juan LI, Wu MH, Shen CJ, Wu JY, Lee CC. Systematic review and meta-analysis of the diagnostic accuracy of procalcitonin, C-reactive protein and white blood cell count for suspected acute appendicitis. Br J Surg 2013;100:322-9.

19. Noh H, Chang SJ, Han A. The diagnostic values of preoperative laboratory markers in children with complicated appendicitis. J Korean Surg Soc 2012;83:237-41.

20. Zhao L, Feng S, Huang S, Tong Y, Chen Z, Wu P, et al. Diagnostic value of hyperfibrinogenemia as a predictive factor for appendiceal perforation in acute appendicitis. ANZ J Surg 2015 Sep 11 [Epub]. http://dx.doi.org/10.1111/ans.13316.

21. Kaser SA, Fankhauser G, Willi N, Maurer CA. C-reactive protein is superior to bilirubin for anticipation of perforation in acute appendicitis. Scand J Gastroenterol 2010;45:885-92.

22. Sand M, Bechara FG, Holland-Letz T, Sand D, Mehnert G, Mann B. Diagnostic value of hyperbilirubinemia as a predictive factor for appendiceal perforation in acute appendicitis. Am J Surg 2009;198:
193-8.

23. Obayashi J, Ohyama K, Manabe S, Tanaka K, Nagae H, Shima H, et al. Are there reliable indicators predicting post-operative complications in acute appendicitis? Pediatr Surg Int 2015 Aug 27 [Epub]. http://dx.doi.org/10.1007/s00383-015-3786-9.

24. Flum DR, Koepsell T. The clinical and economic correlates of misdiagnosed appendicitis: nationwide analysis. Arch Surg 2002;137: 799-804.

25. Humes DJ, Simpson J. Acute appendicitis. BMJ 2006;333:530-4.

26. Paulson EK, Kalady MF, Pappas TN. Clinical practice: suspected appendicitis. N Engl J Med 2003;348:236-42.

27. Ali K, Latif H, Ahmad S. Frequency of wound infection in nonperforated appendicitis with use of single dose preoperative antibiotics. J Ayub Med Coll Abbottabad 2015;27:378-80.

28. Ay N, Dinc B, Alp V, Kaya S, Sevuk U. Comparison of outcomes of laparoscopic intracorporeal knotting technique in patients with complicated and noncomplicated acute appendicitis. Ther Clin Risk Manag 2015;11:1213-6. 